\title{
Thomas Kaufmann, Erlöste und Verdammte. Eine Geschichte der Reformation
}

\section{Gérald Chaix}

\section{OpenEdition}

\section{Journals}

Édition électronique

URL : http://journals.openedition.org/ifha/9112

DOI : 10.4000/ifha.9112

ISSN : 2198-8943

\section{Éditeur}

IFRA - Institut franco-allemand (sciences historiques et sociales)

\section{Référence électronique}

Gérald Chaix, "Thomas Kaufmann, Erlöste und Verdammte. Eine Geschichte der Reformation », Revue de I'IFHA [En ligne], Date de recension, mis en ligne le 14 juin 2018, consulté le 24 septembre 2020. URL : http://journals.openedition.org/ifha/9112 ; DOI : https://doi.org/10.4000/ifha.9112

Ce document a été généré automatiquement le 24 septembre 2020

(CIFHA 


\section{Thomas Kaufmann, Erlöste und Verdammte. Eine Geschichte der Reformation}

Gérald Chaix

\section{RÉFÉRENCE}

Thomas Kaufmann, Erlöste und Verdammte. Eine Geschichte der Reformation, München:

C.H. Beck, 2016, 508 p., 26,95€ 
En trois formules, l'auteur fixe le cadre : la Réformation a été un événement européen; elle était attendue mais la forme qu'elle a prise a été originale; Luther fut à l'origine du processus.

Dans une première partie, Thomas Kaufmann brosse le tableau de la chrétienté européenne à l'aube du XVI ${ }^{e}$ siècle, concentrant pour finir son analyse sur le Saint Empire. Il en rappelle la place spécifique dans une lecture chrétienne et eschatologique de l'histoire (il est le quatrième et dernier des empires), les réformes institutionnelles au tournant des $\mathrm{XV}^{\mathrm{e}}$ et $\mathrm{XVI}^{\mathrm{e}}$ siècles ainsi que les relations conflictuelles avec la Curie romaine (gravamina nationis germanicae). Il évoque les menaces qui pèsent en permanence sur la vie des gens, le dynamisme des universités, la diversité et l'intensité des

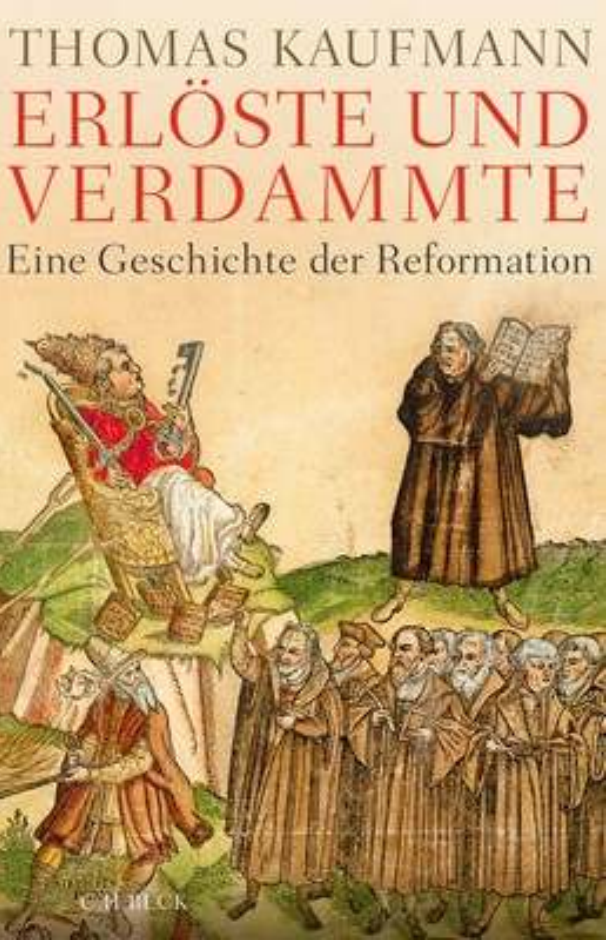
formes de piété, l'apparition de l'imprimerie et la mobilité des humanistes.

Dans une deuxième partie, il étudie la première étape de la Réformation jusqu'aux années 1530. Il peint le portrait nuancé d'un jeune homme incarnant (puis décevant) les ambitions d'une famille en pleine ascension sociale, d'un frère augustin plein de zèle et apprécié, d'un professeur d'université concentré sur sa tâche d'exégète et favorable à une réforme de l'enseignement de la théologie, dont il récuse la démarche scolastique. C'est dans ce cadre qu'il publie ses thèses. Il n'hésite pas à polémiquer sur le terrain de la théologie et répond aux attentes de ses auditeurs et de ses lecteurs, comme en témoigne la diffusion de ses écrits. Le pape qui l'excommunie (Exsurge Domine, Decet Romanum Pontificem) est à ses yeux la figure de l'Antéchrist. La mise au ban de l'Empire à l'issue de la confrontation avec Charles Quint, à la diète de Worms (17-18 avril 1521), fait de lui un héros. Les réformes se multiplient et s'accélèrent dans les villes, en lien avec le mouvement qui se développe à Wittenberg ou de manière plus autonome comme à Zurich. Les campagnes sont également touchées. Les attentes des paysans prennent des formes particulières et suscitent des affrontements qui ébranlent la dynamique réformatrice et écornent l'image de Luther qui apparaît comme le défenseur de l'autorité des princes et qui s'oppose aux théologiens "radicaux », tels Karlstadt et Müntzer. Les événements de 1524/25 constituent un tournant. Le rôle des princes territoriaux devient décisif. La diète d'Augsbourg (1530) est une étape importante. La Confession d'Augsbourg y est présentée.

Dans la troisième partie, T. Kaufmann quitte l'Empire pour esquisser le développement des réformes en Europe jusqu'au début du XVII siècle. Après avoir traité de Jean Calvin et de l'«Internationale réformée», ainsi que des guerres de religion en France, T. Kaufmann revient à la situation allemande. La victoire impériale (Mühlberg, 24 avril 1547 ; Intérim d'Augsbourg) y est de courte durée en dépit de la mort de Luther (18 février 1546). La paix d'Augsbourg entérine l'éclatement confessionnel. Les 
transformations du catholicisme romain accentuent la division. L'existence des courants « radicaux » et " non conformistes ", même si elle reste marginale, souligne la diversité du « protestantisme ». Le bilan est alors tiré en deux temps. Dans le premier, T. Kaufmann souligne le sentiment d'accélération du temps, débouchant tantôt sur l'attente de l'Apocalypse, tantôt sur la conviction d'une rupture. Il dégage les traits de la «modernité occidentale » : les «cultures confessionnelles » et le rôle des laïcs, les mutations économiques et juridiques, l'essor de la rationalité et de l'individualisme. Dans un deuxième temps, T. Kaufmann examine l'écho de la Réformation, des débuts du XVII ${ }^{e}$ siècle jusqu'à nos jours, et retrace les grandes étapes de l'historiographie luthérienne. L'ouvrage est agréablement illustré, propose plusieurs cartes ainsi qu'une copieuse bibliographie et est muni d'un index. Il a été réédité en 2017.

INDEX

Index chronologique : Période moderne

Thèmes : Histoire religieuse ; Histoire des mentalités

\section{AUTEURS}

\section{GÉRALD CHAIX}

Université de Tours, UMR 7323 